\title{
Proximate chemical composition and biological profile of fatty acids of Withania somnifera $L$ dunal
}

\author{
Ghias Uddin ${ }^{1^{*}}$, Abdur Rauf ${ }^{1}$, Sumaira Gul ${ }^{1}$, Muhammad Saleem ${ }^{2}$, Salma Umar ${ }^{2}$ and Ajmal \\ Khan $^{2}$ \\ ${ }^{1}$ Institute of Chemical Sciences, University of Peshawar, Peshawar, KPK, Pakistan. \\ ${ }^{2}$ H.E.J. Research Institute of Chemistry, International Center for Chemical and Biological Sciences, University of \\ Karachi, Karachi-75270, Pakistan.
}

Accepted 26 June, 2013

\begin{abstract}
The fixed oils extracted from the fruit (berry) of Withania somnifera were evaluated for their chemical composition. The gas chromatography-mass spectrometry (GC-MS) analysis shows the presence of various saturated and unsaturated fatty acids present in the roots of Withania somnifera. The total eight fatty acid compounds were identified by GC-MS with the library searches scale with varying percentage such as linoleic acid $(11.247 \%)$, linoleic acid $(4.000 \%)$, palmitic acid, $(2.842 \%)$ and tetracosanoic acid $(0.880 \%)$, palmitic acid $(0.42 \%)$, lenoleic acid $(0.23 \%)$, oleic acid $(0.14 \%)$, elaidic acid $(0.01 \%)$. The fixed oil was evaluated for different biological activities such as phytotoxicity, antibacterial, antifungal, cytotoxicity, antibacterial, and antiurease activities. The oil shows moderate percent inhibition against the entire activities. The oil shows dose dependent DPPH radical scavenging activity.
\end{abstract}

Key words: Withania somnifera, gas chromatography-mass spectrometry (GC-MS), chemical composition, phytotoxicity, cytotoxicity, antimicrobial, diphenylpicrylhydrazyl (DPPH) scavenging, urease assay and inhibition.

\section{INDRODUCTION}

Genus Withania belongs to the family Solanaceae, which comprises 84 genera and more than 3000 species dispersed throughout the world. Berry of Withania somnifera is ingredient of many Ayurveda's and produces successfully developed medicines for tumors, tubercular glands, carbuncles, and ulcers (Mirajalili et al., 2009). Phytochemical studies showed that Aswagandha possesses anti-inflammatory, antitumor, antistress, antioxidant, immunomodulatory, hemopoetic, rejuvenating properties (Lakshmi et al., 2000). It also appears to exert a positive influence on the endocrine, cardiopulmonary, and central nervous system (Lakshmi et al., 2000). The phytochemical screening gave positive results for carbohydrates, alkaloids, glycosides, and fixed oil and fats (Christina et al., 2004). The fruit (berry) of the plant have a milk coagulation property attributed to the pulp and husk of the berry, which has been used in the preparation of vegetable rennent ferment for cheese (Mirajalili et al., 2009). The fruit are reported to be sedative, emetic, and stomachic, a blood-purifier and febrifuge and alternative, diuretic and bitter tonic in dyspepsia as well as growth promoter in infants (Dhuley et al., 1997). Due to the extensively used of $W$. somnifera as a folk medicine for the treatment of various diseases, fixed oils have been extracted from the fruit of $W$. somnifera and checked their biological activities such as phytotoxicity, antibacterial, antifungal, cytotoxicity, antibacterial, and antiurease activities. Here, we are reported for the first time its urease inhibitory and antioxidant activity. 


\section{EXPERIMENTAL}

\section{Chemistry}

Plant

W. somnifera fruit (berry) was collected from Peshawar, Khyber Pakhtunkhwa, Pakistan in month of December, 2011. The plant was identified by taxonomist, from the Department of Botany, University of Peshawar, Pakistan.

\section{Extraction and fractionation}

Shade dried fruit of $W$. somnifera was filled in the flask and extracted successively with methanol solvent in soxhlet extractor for $48 \mathrm{~h}$. The solvent extract was concentrated under reduce pressure at $40^{\circ} \mathrm{C}$ using rotavapor, and suspended in water and successively partitioned with $n$-hexane, chloroform, ethyl acetate and methanolic fraction according to standard protocol (Uddin et al., 2011a; 2012).

\section{Chemicals and reagents}

Boron triflouride solution in methanol (10\%) was obtained from Fluka Chemie (Buchs, Switzerland). Sodium hydroxide solution (methanolic; $0.5 \mathrm{~N}$ ) and sodium chloride (analytical grade) were gotten from Merck (Darmstadt, Germany) while methanol (HPLC grade) and $n$-hexane (HPLC grade) were from Fischer Scientific (Leicestershire, UK). Helium gas (99.9999\%) from Pakistan gas (United Arab Emirates) was procured. Tridecanoic acid methyl ester and fatty acid methyl esters (FAMEs) and 37 component standard mix (methyl ester of hexanoic acid, caprylic acid, capric acid, undecanoic acid, lauric acid, tridecanoic acid, myristic acid, myristoleic acid, pentadecanoic acid, pentdecenoic acid, palmitic acid, palmitoleic acid, margaric acid, hep-tadecenoic acid, stearic acid, oleic acid, elaidic acid, octa- decenoic acid, linoleic acid, octadecadienoic acid, g-lino-lenic acid, linolenic acid, arachidic acid, eicosenoic acid, eicosadienoic acid, 8,11,14-eicosatrienoic acid, heneico-sanoic acid, arachidonic acid, eicosatrienoic acid, eicosa-pentaenoic acid, behenic acid, eruccic acid, docosadienoic acid (C22:2), tricosanoic acid, tetracosanoic acid, docosahexaenoic acid and tetracosenoic acid) were acquired from AccuStandard (Newhaven, Connecticut USA).

\section{Preparation of standard}

Internal standard was prepared by dissolving $13.7 \mathrm{mg}$ of tridecanoic acid methyl ester in $1 \mathrm{ml}$ hexane. External standard was prepared by diluting $10 \mathrm{mg}$ of 37 component FAMEs mix standard to $10 \mathrm{ml}$ with dichloromethane. From the stock solution further working solutions were prepared.

\section{Extraction of oil from fruit and preparation of FAMEs}

The shade dried and crushed fruit of $W$. somnifera $(100 \mathrm{~g})$ was subjected to cold extraction with $\mathrm{MeOH}(3 \times 10 \mathrm{~L})$ at room temperature. The extract was then concentrated under reduced pressure at temperature below $40^{\circ} \mathrm{C}$. The final residue obtained was $25 \mathrm{~g}$. This methanolic extract was suspended in water and successively partitioned with $\mathrm{n}$-hexane, chloroform, EtOAc. The hexane fraction $(4 \mathrm{~g})$ was subjected to column chromatography on silica gel (Merck Silica gel $60(0.063-0.200 \mathrm{~mm}), 5 \times 60 \mathrm{~cm})$. The column was eluted with $n$-hexane: EtOAc $(100: 0 \rightarrow 0: 5)$ as solvent system. A total of 20 fractions, $\mathrm{RO}-1$ to $\mathrm{RO}-20$ were obtained based on thin layer chromatography (TLC) profiles. Fraction RO-1 to RO-3 contained yellow coloured oil. Yield: $(0.60 \mathrm{~g})$.

\section{Preparation of FAMEs}

For gas chromatographic analysis, it is required that the sample being analyzed must be volatile. For the identifications of FAMES, along with other volatile organic compounds the oil were directly subjected to GC-MS. To identify fatty acid, the following procedures were adapted. In order to make fatty acids present in the oil volatile, derivitization of oil was performed prior to GC-MS analysis. Methylation general method was used for converting non-volatile fatty acids into volatile FAMEs (Vickery, 1981). Methylation of fatty acids was achieved with $\mathrm{BF}_{3}$-methanol as derivatizing reagent, which is the accepted procedure for converting fatty acids into FAMEs. Derivitization was done according to the AOAC standard reference method (Yue et al., 2010). To a known amount of sample (equivalent to $25 \mathrm{mg}$ fat) was added $0.1 \mathrm{ml}$ internal standard $(1.37 \mathrm{mg})$ and $1.5 \mathrm{ml}$ of sodium hydroxide solution in methanol $(0.5 \mathrm{~N})$, sealed and heated in boiling water bath for $5 \mathrm{~min}$. The hydrolyzed sample was cooled and added $2.5 \mathrm{ml}$ of boron triflouride solution in methanol (10\%). The solution was then sealed and heated in boiling water bath for $30 \mathrm{~min}$ and then cooled. To the esterified solution was added $5 \mathrm{ml}$ saturated sodium chloride solution and extracted twice with $1 \mathrm{ml}$ hexane. The hexane extract was filtered through $0.45 \mathrm{~m}$ membrane filter and injected $1 \mu \mathrm{l}$ to GC-MS using auto injector system.

\section{Chromatographic separation of FAMEs}

Gas chromatograph (Shimadzu) hyphenated to a mass spectrometer QP 2010 plus (Tokyo, Japan) equipped with an autosampler (AOC-20S) and auto-injector (AOC-20i) was used for analysis of fatty acid. Helium was used as carrier gas. All chromatographic separations were performed on a capillary column (TRB-FFAP; Technokroma) having specifications: length, $30 \mathrm{~m}$; ID, $0.35 \mathrm{~mm}$; thickness, $0.250 \mu \mathrm{m}$; treated with polyethylene glycol. Other GC-MS conditions are ion source temperature $(\mathrm{El}): 250^{\circ} \mathrm{C}$, interface temperature: $240^{\circ} \mathrm{C}$, pressure: $100 \mathrm{KPa}$, solvent cut time: $1.6 \mathrm{~min}$. One microlitre of sample and standard were injected into the GC column. Injector was operated in a split mode with a split ratio 1:50. Injection temperature was $240^{\circ} \mathrm{C}$. The column temperature program started at $50^{\circ} \mathrm{C}$ for $1 \mathrm{~min}$ and changed to $150^{\circ} \mathrm{C}$ at the rate of $15^{\circ} \mathrm{C} \mathrm{min}$. The temperature was raised to $175^{\circ} \mathrm{C}$ at the rate of $2.5^{\circ} \mathrm{C} / \mathrm{min}$ and held for 5 minutes. Then the temperature was increased to $220^{\circ} \mathrm{C}$ at the rate of $2.5^{\circ} \mathrm{C} / \mathrm{min}$ and kept constant for 5 minutes. Total elution time was 45 minutes. MS scanning was performed from $\mathrm{m} / \mathrm{z} 85$ to $\mathrm{m} / \mathrm{z}$ 380. GC-MS solutions software provided by the supplier was used to control the system and to acquire the data. Identification of the compounds was carried out by com-paring the mass spectra obtained with those of standard mass spectra from the NIST library (NIST 05) (Zhao et al., 2006).

\section{Biological assays}

\section{Urease assay and inhibition}

Reaction mixtures comprising $25 \mu \mathrm{l}$ of enzyme (jack bean urease) solution and $55 \mu \mathrm{l}$ of buffers containing $100 \mathrm{mM}$ urea were incubated with $5 \mu \mathrm{l}$ of test compounds $(0.5 \mathrm{mM}$ concentration) at $30^{\circ} \mathrm{C}$ for $15 \mathrm{~min}$ in 96 -well plates. Urease activity was determined by measuring ammonia production using the indophenol method as described by weather burn. Briefly, $45 \mu$ l each phenol reagent $(1 \%$ 
$\mathrm{w} / \mathrm{v}$ phenol and $0.005 \% \mathrm{w} / \mathrm{v}$ sodium nitroprussside) and $70 \mu \mathrm{l}$ of alkali reagent $(0.5 \% \mathrm{w} / \mathrm{v} \mathrm{NaOH}$ and $0.1 \%$ active chloride $\mathrm{NaOCl})$ were added to each well. The increasing absorbance at $630 \mathrm{~nm}$ was measured after $50 \mathrm{~min}$, using a microplate reader (Molecular Device, USA). All reactions were performed in triplicate in a final volume of $200 \mu \mathrm{l}$. The results (change in absorbance per min) were processed by using softMax Pro software (molecular Device, USA). The entire assays were performed at $\mathrm{pH}$ 6.8. Percentage inhibitions were calculated from the formula $100-\left(O D_{\text {testwell }} / O D_{\text {control }}\right) \times 100$. Thiourea was used as the standard inhibitor of urease (Arfan et al., 2010).

\section{Antibacterial assay}

Three strains of Gram-positive bacteria (Staphylococcus aureus, Strap epidermis and Bacillus subtilis) and two of Gram-negative bacteria (Escherichia coli and Klebsiella pneumonia) is earlier discuss (Uddin et al., 2011b), obtained from PNRL laboratories, Institute of Chemical Sciences, University of Peshawar, Peshawar, Pakistan were used in the present study. These organisms were kept in Müller-Hinton agar in the refrigerator at $4^{\circ} \mathrm{C}$, prior to subculture. Tests for susceptibility were done using modified agar well diffusion method to test the antibacterial activity of the oil. The Muller-Hinton agar was used as medium. The cultures were taken in triplicates at incubation temperature of $37^{\circ} \mathrm{C}$ for 24 to $72 \mathrm{~h}$. The broth culture $(0.6 \mathrm{ml})$ of the test organism was placed in a sterile Petri-dish to which $20 \mathrm{ml}$ of the sterile molten Muller-Hinton agar was added. Holes were bored in to the medium using $0.2 \mathrm{ml}$ of the oil. Streptomycin was the standard antimicrobial agent at a concentration of $2 \mathrm{mg} / \mathrm{ml}$. Inoculation was done for $1 \mathrm{~h}$ to make possible the diffusion of the antimicrobial agent into the medium. Incubation was done at $37^{\circ} \mathrm{Cfor} 24 \mathrm{~h}$ and the diameters of the zone of inhibition of microbial growth were measured in the plate in millimeter.

\section{Insecticidal activity}

Oil isolated from fruits was investigated against various insects such as Tribolium castaneum, Rhyzopertha dominica and Callosobruchus analis according to standard protocol (Uddin et al., 2011c). The test sample was prepared by dissolving 1019.10 $\mu \mathrm{g} / \mathrm{cm}^{2}$ of oil in $3 \mathrm{ml}$ acetone and loaded in a Petri dish covered with the filter papers. After duration of $24 \mathrm{~h}, 10$ test insects were put in each plate and incubated at temperature $27^{\circ} \mathrm{C}$ for $24 \mathrm{~h}$ duration with $50 \%$ relative humidity in growth chamber. The results were evaluated as percentage mortality, calculated with reference to the positive and negative controls. In this bioassay study, permethrin was used as a standard drug, while permethrin, acetone and test insects were used as positive and negative controls. The percentage mortality was calculated by using the formula:

$$
\text { Growth regulation }(\%)=\frac{\text { Number of insect alive in test }}{\text { Number of insect alive in control }} \times 100
$$

\section{Cytotoxicity bioassay}

Method used in current study is very simple for determination of cytotoxicity of oil of $W$. somnifera. In this bioassay, artificial "sea water" was prepared by dissolving $38 \mathrm{~g}$ sea salt per liter of double distilled water and filtered "Sea water" was put in a small tank, and brine-shrimp eggs ( $1 \mathrm{mg}$ ) (Artemia salina) was added and was kept covered by covering with aluminum foil to provide darken condition. It was allowed to stand for duration of $24 \mathrm{~h}$ at $25^{\circ} \mathrm{C}$ which provided a large number of larvae. Twenty milligrams of the concentrated sample was dissolved in $2 \mathrm{ml} \mathrm{CHCl} 3(20 \mathrm{mg} / 2 \mathrm{ml})$ and transferred to 500,50 and $5 \mu \mathrm{l}$ vials corresponding to 1000,100 and $10 \mu \mathrm{g} / \mathrm{ml}$, respectively. Then three replicates were prepared for each concentration making a total of nine vials. The material in these vials was concentrated, dissolved in DMSO $(50 \mu \mathrm{l})$ and $5 \mathrm{ml}$ "sea water" added to each. Then 10 shrimps were added to each vial and were allowed to stand for $24 \mathrm{~h}$ duration, the result was calculated and the number of surviving shrimps was noted. Etoposide was used as positive control (Rauf et al., 2012).

\section{DPPH free radical scavenging assay}

Twenty-five milligrams of oil was taken and dissolved in distilled methanol and diluted up to $50 \mathrm{ml}$ as discussed earlier (Uddin et al., 2012). From this stock solution different micrograms solution of 10 , $20,40,60,80$ and $100 \mu \mathrm{g} / \mathrm{ml}$ were prepared by dilution method. 5 $\mathrm{ml}$ of each solution was taken in a test tube and $1 \mathrm{ml}$ of $0.001 \mathrm{M}$ of DPPH solution was added to it. All these solutions were kept in dark for $30 \mathrm{~min}$. Also, $5 \mathrm{ml}$ methanol was taken and $1 \mathrm{ml}$ of DPPH solution was added, for control solution. At the end of incubation period the mixtures were examined for the antioxidant activity using Optima UV-Visible spectrophotometer at wavelength of $517 \mathrm{~nm}$ (Uddin et al., 2011c). The experiments were performed with triplicate readings. Percent DPPH was determined using the formula as follows:

RSA $(\%)=$ Control abs - Extract abs $\times 100 /$ Control.

\section{RESULTS AND DISCUSSION}

The GC-MS analysis of the fruits of $W$. somnifera resulted in the identification of total 8 components as presented in the Tables. The major constituents among the identified constituents were linoleic acid, methyl ester (11.247\%), linoleic acid, ethyl ester (4.000\%), palmitic acid, methyl ester $(2.842 \%)$ and tetracosanoic acid, methyl ester $(0.880 \%)$. The remaining detail of the chemical composition is shown in Table 1. Total of eight components were identified using GC-MS analysis. The major constituent of the fruits fixed oils were palmitic acid $(0.42 \%)$, lenoleic acid $(0.23 \%)$, oleic acid $(0.14 \%)$, stearic acid $(0.10 \%)$, myristic acid $(0.03 \%)$, hexanoic acid $(0.01 \%)$, lauric acid $(0.01 \%)$, and elaidic acid $(0.01 \%)$. The IR spectroscopy of oils was recorded which it showed the presence of different functional groups. The IR gives broad signal at 33950, 3340 and 3299 which indicate the presence of $\mathrm{OH}$ stretching. The IR gives strong signals at 2997, and 2990 which indicated the presence $\mathrm{CH}$ stretching saturated. A weak signal observed at 2884 indicates the presence of carboxylic acid. The strong signal observed at the 1695 indicate the presence of $\mathrm{C}=\mathrm{O}$. After IR characterization the fixed oil was subjected to different biological activities such as antifungal, antibacterial, urease inhibition and DPPH radical scavenging activities (Table 2 to 7 ). The fixed oil shows dose dependent response in DPPH radical scavenging activity, which indicates that fixed oil, has good antioxidant activity (Table 2). The percent inhibitions of fixed oil against antioxidant at different 
Table 1. Chemical composition of fixed oils.

\begin{tabular}{clcccc}
\hline ID No. & Name & Retention time & Area & Concentration (\%) & Standard deviation \\
\hline 1 & C6:0; Hexanoic acid, methyl ester & 3.033 & 1014 & 0.01 & 0.002 \\
5 & C12:0; Lauric acid, methyl ester & 8.505 & 2409 & 0.01 & 0.003 \\
7 & C14:0; Myristic acid, methyl ester & 10.921 & 11018 & 0.03 & 0.001 \\
11 & C16:0; Palmitic acid, methyl ester & 14.563 & 149557 & 0.42 & 0.020 \\
15 & C18:0; Stearic acid, methyl ester & 19.534 & 28818 & 0.10 & 0.010 \\
16 & C18:1c; Oleic acid, methyl ester & 20.066 & 10936 & 0.14 & 0.003 \\
17 & C18:1n9T; Elaidic acid, methyl ester & 20.307 & 649 & 0.01 & 0.004 \\
18 & C18:2c; Linoleic acid, methyl ester & 21.646 & 17946 & 0.23 & 0.004 \\
\hline
\end{tabular}

Table-2. DPPH radical scavenging assay of fixed oil of Withania somnifera.

\begin{tabular}{cc}
\hline Concentration of fixed oil (ppm) & RSA (\%) \\
\hline 10 & 3.54 \\
20 & 8.52 \\
40 & 12.32 \\
60 & 15.21 \\
80 & 30.22 \\
100 & 58.52 \\
\hline
\end{tabular}

RSA: Radical scavenging assay.

Table 3. Antifungal activity of oil extracted from fruits of Withania somnifera.

\begin{tabular}{lclc}
\hline Fungal strain & Inhibition of fixed oil () & Standard drug & $\mathbf{M I C}(\boldsymbol{\mu g} / \mathbf{m l})$ \\
\hline C. albicans & - & Miconazole & 110.8 \\
A. flavus & - & Amphotericin-B & 20.20 \\
M. canis & 25 & Miconazole & 98.4 \\
F. solani & 20 & Miconazole & 73.25 \\
C. glabarata & - & Miconazole & 110.8 \\
C. albicans & - & Miconazole & 110.8 \\
A. flavus & - & Amphotericin-B & 20.20 \\
\hline
\end{tabular}

MIC: Minimum inhibitory concentration.

Table 4. Cytotoxicity data for oil extracted from the fruit of Withania somnifera.

\begin{tabular}{|c|c|c|c|c|c|c|}
\hline $\begin{array}{c}\text { Dose } \\
(\mu \mathrm{g} / \mathrm{ml})\end{array}$ & $\begin{array}{c}\text { No. of } \\
\text { shrimps }\end{array}$ & $\begin{array}{c}\text { No. of } \\
\text { survivors }\end{array}$ & $\begin{array}{c}\text { No. of } \\
\text { larvae died }\end{array}$ & $\mathrm{LD}_{50}(\mu \mathrm{g} / \mathrm{ml})$ & $\begin{array}{l}\text { Standard } \\
\text { drug }\end{array}$ & $\mathrm{LD}_{50}(\mu \mathrm{g} / \mathrm{ml})$ \\
\hline \multicolumn{7}{|c|}{ Fixed oil } \\
\hline 10 & 30 & 28 & 02 & & & \\
\hline 100 & 30 & 29 & 01 & - & Etoposide & 7.4625 \\
\hline 1000 & 30 & 30 & 0 & & & \\
\hline
\end{tabular}

concentrations are presented in Figure 1. The antifungal activities of the fixed oil are listed in Table 3, which showed weak inhibition against the two strains of fungi. The fixed oil showed percent inhibition of 25 and 20 against the Microsporum canis and Fusarium solani, respectively. The cytotoxicity and phytotoxicity profile of fixed oil shows that it is non-toxic as compared to standard toxic drug (Tables 4 and 5). The fixed oil was 
Table 5. Phytotoxic profile of oil extracted from fruit of Withania somnifera.

\begin{tabular}{ccccc}
\hline Sample & $\begin{array}{c}\text { Concentration }(\boldsymbol{\mu g} / \mathrm{ml}) \\
\text { of sample }\end{array}$ & $\begin{array}{c}\text { Fronds } \\
\text { survived }\end{array}$ & $\begin{array}{c}\text { Fronds } \\
\text { died }\end{array}$ & $\begin{array}{c}\text { Growth regulation } \\
(\%)\end{array}$ \\
\hline \multirow{3}{*}{ Fixed oil } & 10 & 20 & 0 & 0 \\
& 100 & 20 & 0 & 0 \\
\hline
\end{tabular}

Table 6. Antibacterial profile of oil extracted from Withania somnifera.

\begin{tabular}{lccc}
\hline \multirow{2}{*}{ Bacterial strain } & \multicolumn{4}{c}{ Zone of inhibition $(\mathbf{m m}$ at $\mathbf{3} \mathbf{~ m g} / \mathbf{m l})$} \\
\cline { 2 - 5 } & Zoon of inhibition of fixed oil at $\mathbf{2 5} \boldsymbol{\mu g}$ disc & Standard drug (Imipenum) & DMSO \\
\hline E. coli & 7 & 28 & - \\
B. subtilus & 8 & 26 & - \\
S. flexenari & - & - & - \\
\hline
\end{tabular}

DMSO: A negative control.

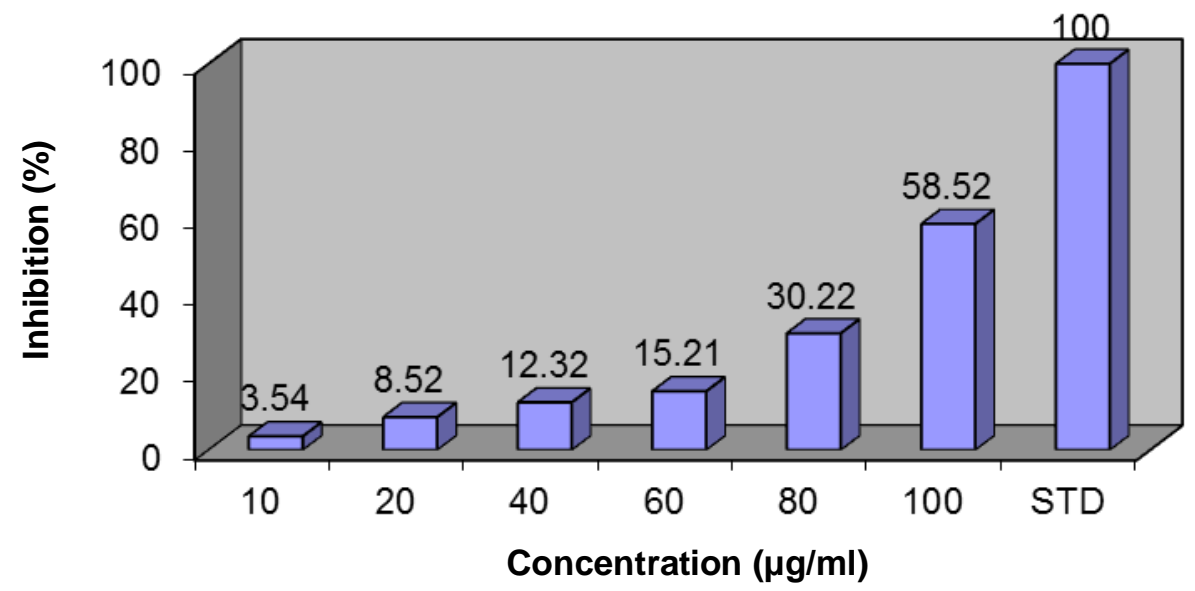

Figure 1. DPPH radical scavenging activities of the fixed oil of Withania somnifera.

Table 7. Urease assay and inhibition activities of fixed oil of Withania somnifera roots.

\begin{tabular}{lc}
\hline Sample (Fixed oil) & Inhibition (\%) \\
\hline SMS-1 & 39.0 \\
Standard (thiourea) & 98.2 \\
\hline
\end{tabular}

also evaluated for the antibacterial activity against the three strains of bacteria (Escherichia coli, Bacillus subtillis, Shigella flexenari). The fixed oil showed weak inhibition of 7 and 8 against $E$. coli and B. subtilis, respectively at $25 \mu \mathrm{g}$ disc (Table 6 ). The fixed oil showed good inhibition with $39.0 \%$ against urease enzyme inhibition studies. For the first time, the urease inhibitory activity of fixed oil from $W$. somnifera was reported. Further research on isolation of fixed oils may result in a leading research in the field of drug discovery.

\section{REFERENCES}

Arfan M, Ali M, Ahmad H, Anis I, Khan A, Choudhary MI, Shah MR (2010). Urease inhibitors from Hypericum oblongifolium wall. J. Enzyme Inhab. Med. Chem. 25:296-299.

Christina AJM, Joseph DG, Packialakshmi M, Kothai R (2004). Anticarcenogenic activity of Withania somnifera Dunal against Daltons Ascitic Lymphoma. J. Ethnopharmacol. 93:359-361.

Dhuley JN (1997). Effect of some Indian herbs on microphage functions in ochratoxin A treated mice. J. Ethnopharmacol. 58(1):15-20.

Lakshmi CM, Besty BS, Simon D (2000). Scientific basis for therapeutic use of Withania somnifera, A Review, Int. Soc. Horticult. Sci. pp. 334346.

Mirajalili MH, Monyano E, Bonfill M, Cusido RM, Palazon J (2009). Steroidal Lactones from withania somnifera, an ancient plant for novel Medicine. Molecular 14:2373-2393.

Rauf A, Khan A, Rasool S, Shah ZA, Withania S, Saleem M (2012). "In vitro Antifungal Activity of Three Selected Pakistani Medicinal Plants. Middle-East J. Med. Plants Res. 1:41-43.

Uddin G, Rauf A, Qaisar M, Latif A, Ali M (2011b). Preliminary Phytochemical Screening and Antimicrobial Activity of Hedera helix L. Middle-East J. Sci. Res. 8:198-202.

Uddin G, Rehman TU, Liaquat W, , Ullah W, Rauf A, Khan I, 
Mohammad G, Choudhary MI (2011c). In-vitro pharmacological investigation of aerial parts of indigofera heterantha. J. Med. Plants Res. 5:5750-5753.

Uddin G, Rauf A, Rehman TU, Qaisar M (2011a). Phytochemical Screening of Pistacia chinensis var. integerrima. 2011. Middle-East J. Sci. Res. 7:707-711.

Uddin G, Rauf A (2012). Phytochemical screening, antimicrobial and antioxidant activities of aerial parts of Quercus robur L. Middle-East J. Med. Plants Res. 1:01-04.

Vickery JR (1981). The occurrence of dihydromalvalic acid in some seed oils. J. Am. Oil Chem. Soc. 58:731-732.
Yue XF, Zhang YN, Zhang J, Zhang ZQ (2010). Free fatty acids profile analysis of alcohol extract of Aconitum taipeicum Hand.-Mazz with gas chromatography-mass spectrometry, Analytical Methods 2:668-672.

Zhao JS, Li P, Yang FQ, Li P, Wang YT (2006). Simultaneous determination of saponins and fatty acids in Ziziphus jujuba (Suanzaoren) by high performance liquid chromatographyevaporative light scattering detection and pressurized liquid extraction. J. Chromatogr. A. 1108:188-194. 